\title{
A SENTENÇA DE MÉRITO PROLATADA COM A PRETERIÇA̧O DO(S) LITISCONSORTE(S) NECESSÁRIO(S) UNITÁRIO(S): UMA ANÁLISE SOB A ÓTICA DOS PLANOS DOS ATOS PROCESSUAIS
}

THE JUDGMENT OF MERIT PROLATED WITH THE PRETERMISSION OF THE NECESSARY UNITARY COLLEGITIMATE: AN ANALYSIS FROM THE POINT OF VIEW OF THE PLANS OF THE PROCEDURAL ACTS

\section{Lisiane Beatriz Fröhlich}

Especializanda em Direito Público pela Fundação Escola Superior do Ministério Público - FMP/RS (Porto

Alegre/Brasil). Graduada em Direito pela Universidade Feevale (Novo Hamburgo/Brasil).

E-mail: lisibfro@gmail.com.

\section{Jonathan lovane de Lemos}

Mestre em Direito e Especialista em Direito Processual Civil pela Pontifícia Universidade Católica do Rio Grande do Sul (Porto Alegre/Brasil). Docente na Universidade Feevale (Novo Hamburgo/ Brasil). Advogado. E-mail: jonathanlemos@feevale.br. 


\section{RESUMO}

O presente estudo tem como objetivo geral compreender em qual dos planos dos atos processuais - existência, validade ou eficácia - reside o defeito que acomete a sentença de mérito prolatada com a preterição do(s) litisconsorte(s) necessário(s) unitário(s). A partir dos resultados obtidos com a pesquisa, constatou-se que, para o alcance de uma conclusão satisfatória a seu respeito, é imprescindivel a verificação do momento em que é alegada a preterição do(s) litisconsorte(s) necessário(s) unitário(s). Assim, concluiu-se que, na eventualidade de a alegação ocorrer anteriormente ao trânsito em julgado, o defeito estará situado no plano da validade, tratando-se de uma nulidade absoluta. Por outro lado, após o trânsito em julgado, o que remanesce é o vício no plano da eficácia. Dessa forma, observa-se que a atual legislação processual civil não é incorreta, mas incompleta e carente de precisão. Isso porque, apesar da superlativa importância da definição do momento em que se está analisando o vício, o Código de Processo Civil de 2015 é omisso com relação a esse aspecto, potencializando as dúvidas a respeito do tema. Por fim, verificou-se que, devido à gravidade do defeito que acomete essa sentença - oriunda, sobretudo, da ofensa aos princípios constitucionais - , é possível que qualquer interessado o alegue. Além disso, pelos mesmos motivos, as vias processuais admissíveis para combater esse vício são variadas, podendo ser manejada a ação rescisória, a impugnação ao cumprimento de sentença, a querela nullitatis insanabilis ou, ainda, qualquer outro meio idôneo e compatível com a situação concreta.

Palavras-chave: Litisconsórcio necessário unitário. Sentença de mérito. Inexistência. Invalidade. Ineficácia.

\section{ABSTRACT}

The purpose of the present study is to understand in which of the plans of procedural acts - existence, validity or efficacy - is situated the defect that affects the judgment of merit prolated with the pretermission of the necessary unitary collegitimate. From the results obtained with the research, it was verified that, in order to arrive at a satisfactory conclusion about it, it is essential to verify the moment when is alleged the omission of the necessary unitary collegitimate. Thus, it was concluded that, if the claim occurs before it is formed the res judicata, the defect is situated in the validity plan, being an absolute nullity. On the other hand, after the res judicata is formed, what remains is the inefficacy. Therefore, it was verified that the current civil procedural law is not incorrect, but incomplete and lacking precision. This is because, in spite of the superlative importance of defining which moment the defect is being analyzed, the Brazilian Civil Procedure Code of 2015 do not consider this aspect, potentializing doubts about the issue. Finally, it was discovered that, because of the severity of the defect that affects this veredict - originated, principally, from the offense to the constitutional principles - it is possible that any interested subject of the process can claim it. Besides that, for the same reasons, it is admitted the use of several procedural means to combat this decision, like the rescissory action, the enforcement's impugnment of the judgment, the querela nullitatis insanabilis or any other suitable procedural means and compatible with the specific situation.

Keywords: Necessary unitary joinder of parties. Judgment of merit. Inexistence. Invalidity. Inefficacy. 


\section{METODOLOGIA}

Para o desenvolvimento do presente artigo utilizou-se a metodologia descritiva, desenvolvida sob os métodos histórico, dedutivo e comparativo, buscando examinar, interpretar e compreender conceitos, princípios e aspectos técnicos que envolvem a temática desde a sua origem até a atualidade. Ademais, considerando a existência de ampla bibliografia acerca do objeto de estudo que, no entanto, apresenta significativas divergências de entendimentos, analisou-se a temática sob a ótica de muitas críticas.

\section{INTRODUÇÃO}

É frequente, no atual momento do direito processual civil brasileiro, a existência de aprofundados debates em relação às alterações trazidas pelo Código de Processo Civil de 2015 (Lei n 13.105/2015). Parcela dessas discussões é originada pelo instituto do litisconsórcio, cujos fundamentos básicos são: a harmonia entre os julgados e a economia processual. Em razão disso, as legislações são propensas a admitir o litisconsórcio e, em certas oportunidades, a exigi-lo, como é o caso do litisconsórcio necessário. O problema ocorre quando é prolatada a sentença de mérito sem a formação do litisconsórcio exigido por lei, sendo que a decisão teria de ser uniforme em relação a todos os que deveriam ter integrado o processo.

Dessa forma, o objetivo geral do presente estudo é justamente compreender em qual dos planos dos atos processuais - existência, validade ou eficácia - reside o defeito que acomete a sentença de mérito prolatada com a preterição do(s) litisconsorte(s) necessário(s) unitário(s). Para tanto, utilizou-se a metodologia descritiva, desenvolvida sob os métodos histórico, dedutivo e comparativo, buscando examinar, interpretar e compreender conceitos, princípios e aspectos técnicos que envolvem a temática desde a sua origem até a atualidade.

Realizadas essas considerações iniciais e com o fito de alcançar o objetivo da pesquisa, o artigo está organizado em três seções. As duas primeiras destinam-se à análise dos defeitos dos atos processuais e do litisconsórcio, constituindo verdadeiros alicerces para o entendimento da terceira, na qual será compreendido em qual dos planos dos atos processuais está situado o vício contido na sentença de mérito prolatada com a ausência do(s) litisconsorte(s) necessário(s) unitário(s). 


\section{OS DEFEITOS DOS ATOS PROCESSUAIS}

Esta seção destina-se ao estudo dos defeitos dos atos processuais, abrangendo os seus três planos - existência, validade e eficácia. Para tanto, será estruturado de modo a permitir a assimilação das noções fundamentais dos atos processuais, os seus defeitos e os princípios gerais a eles pertinentes.

\subsection{NOÇÕES FUNDAMENTAIS SOBRE OS ATOS PROCESSUAIS}

A noção de ato processual é de fundamental importância para a compreensão da entidade complexa denominada processo, uma vez que este último é formado por um conjunto de atos organizados com o propósito de obter-se uma decisão final (DIDIER JÚNIOR, 2015; FAZZALARI, 2006). Com o intuito de evitar confusões conceituais entre os termos processo e procedimento, Cândido Rangel Dinamarco explica que o processo é composto pela associação de dois fatores: a relação jurídica processual e o procedimento. Enquanto que o procedimento, por seu turno, é o componente visivel do processo, revelando-se em atividades concretas e consistindo em um conjunto de atos concatenados com o escopo de alcançar a obtenção de uma tutela jurisdicional justa (DINAMARCO, 2005).

Com efeito, compreendendo-se o processo como uma sequência de atos concatenados logicamente, admite-se a possibilidade de estudá-lo a partir da análise individualizada destes (WAMBIER; TALAMINI, 2015). Nesse quadro, é relevante destacar que os atos processuais são espécies do gênero atos jurídicos que, por sua vez, integram o conceito amplo de fato jurídico (MELLO, 2012). Contudo, a tentativa de definir em qual aspecto reside a diferença existente entre a espécie ato processual e o gênero ato jurídico gera verdadeiro imbróglio doutrinário (PASSOS, 2002).

As principais divergências doutrinárias que permeiam a definição do ato processual sucedemse em razão de alguns entenderem que, para o ato ser considerado processual, faz-se necessário que ele, alternativamente: (i) tenha a sua eficácia limitada ao âmbito do processo; (ii) se realize na sede do processo; ou (iii) se vincule aos sujeitos do processo. Todavia, tais considerações mostram-se insuficientes, fazendo-se necessária uma combinação desses elementos para atingir a plenitude conceitual. Assim, em consonância com o entendimento de José Joaquim Calmon de Passos (PASSOS, 2002), Cândido Rangel Dinamarco acentua que o ato processual consiste, ao fim e ao cabo, em uma "conduta humana voluntária, realizada no processo por um dos seus sujeitos e dotada da capacidade de produzir efeitos sobre este" (DINAMARCO, 2005, p. 475).

Adotando-se a classificação sugerida por Marcos Bernardes de Mello, é possivel traçar a taxonomia dos fatos jurídicos lícitos em sentido amplo, que têm como espécies o fato processual, o ato-fato jurídico 
e o ato jurídico em sentido amplo. Ainda, consideram-se subespécies de ato jurídico em sentido amplo, o ato processual e o negócio jurídico. Desse modo, seguindo essa estrutura organizacional, permite-se a visualização do presente estudo da seguinte forma (MELLO, 2012, p. 146-163).

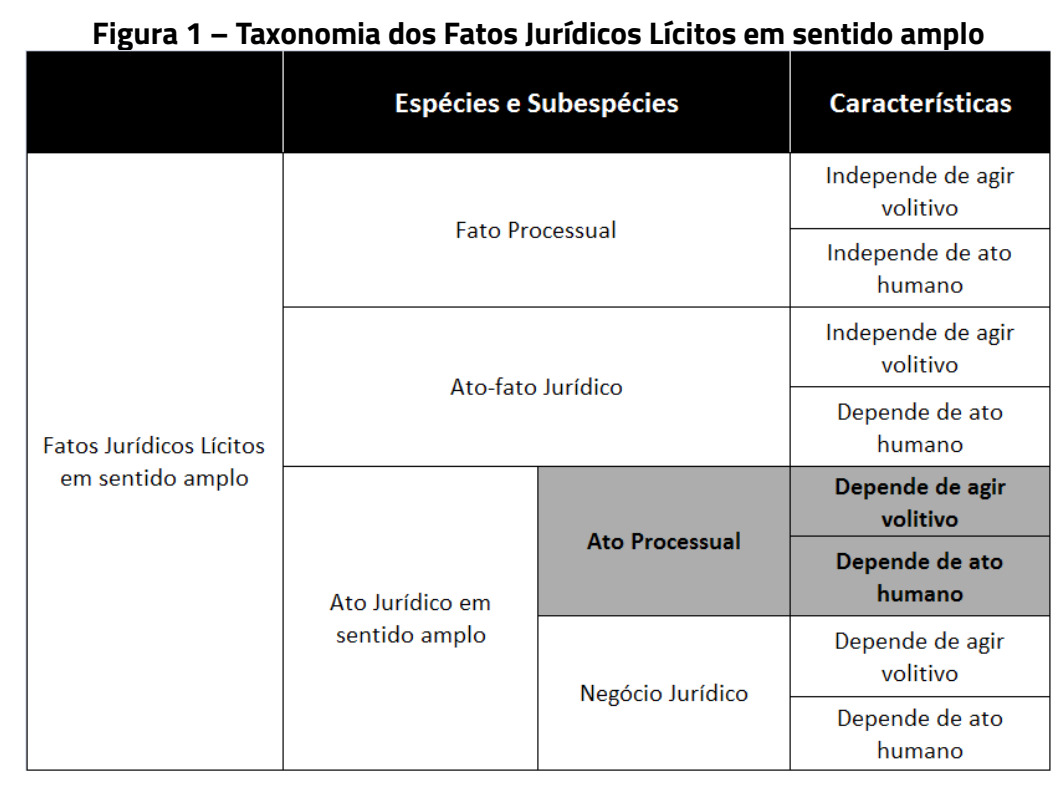

Fonte: Compilação dos autores a partir de Marcos Bernardes de Mello.

Note-se que, conforme se depreende da figura acima, os elementos decisivos para essa classificação consistem na existência, ou não, de conduta humana e de agir voluntário. Assim, embora o fato processual e o ato-fato jurídico possuam a característica comum de independerem de ato volitivo, diferenciam-se, sobretudo, em razão de o primeiro prescindir de ato humano e o segundo possuir essa característica como base (CUNHA, 2015).

No que se refere ao ato jurídico, percebe-se que ele se diferencia do fato processual em razão dos dois elementos. Por outro lado, o elemento distintivo em relação ao ato-fato processual consiste na dependência de uma conduta voluntária. Ainda, observa-se que, tanto para o ato processual quanto para o negócio jurídico, é imprescindivel a existência dos dois fatores e, consoante exposto alhures, eles se distinguem, principalmente, em razão da existência, ou não, de autonomia para estabelecer os efeitos decorrentes da sua prática (GAIO JÚNIOR, GOMES e FAIRBANKS, 2017).

Realizadas essas considerações sobre os atos processuais, resta delimitado o âmbito de incidência do estudo atinente aos seus defeitos. Dessa forma, cumpre verificar com maior profundidade os defeitos 
dos atos processuais sob o enfoque dos planos da existência, da validade e da eficácia, identificando as suas particularidades.

\title{
1.2 DEFEITOS DOS ATOS PROCESSUAIS: ANÁLISE DOS PLANOS DA EXISTÊNCIA, DA VALIDADE E DA EFICÁCIA
}

Uma vez traçadas as noções fundamentais acerca dos atos processuais, ingressa-se no estudo dos seus defeitos. Para tanto, realizar-se-á a análise dos três planos do mundo jurídico - existência, validade e eficácia. Essa divisão tem as suas raízes na obra de Francisco Cavalcanti Pontes de Miranda e é utilizada até os dias atuais (TESHEINER, 2000). Para o autor, o mundo jurídico é composto da seguinte forma:

\begin{abstract}
No mundo jurídico, há três planos diferentes: o plano da existência, em que há fatos jurídicos (fj), e não mais suportes fáticos; o plano da validade, quando se trata de ato humano e se assenta que é válido, ou não-válido (nulo ou anulável); o plano da eficácia, em que se irradiam os efeitos dos fatos jurídicos: direitos, deveres; pretensões, obrigações; ações, em sua atividade (posição de autor) e em sua passividade (posição de réu); exceções (PONTES DE MIRANDA, 1999, p. 22).
\end{abstract}

Segundo Cândido Rangel Dinamarco, o ato processual será considerado inexistente, inválido ou ineficaz de acordo com a gravidade do vício que o acomete (DINAMARCO, 2005). Não se pode olvidar, portanto, que existir, valer e ser eficaz consistem em circunstâncias distintas e reverberam consequências que são peculiares a cada um dos planos do mundo jurídico (MELLO, 2012).

No tocante à terminologia utilizada no presente estudo, esclarece-se que, no mesmo sentido do entendimento de Leonardo Greco, o termo "defeito" é utilizado como sinônimo de "vício". Dessa forma, ambos dizem respeito a quaisquer das imperfeições dos atos processuais, independentemente do plano em que se situam (GRECO, 2015, p. 371).

Costuma-se dizer que há uma sucessão lógica entre os planos da existência, da validade e da eficácia (CABRAL, 2010). Nesse sentido, tem-se que a passagem do ato processual pelo primeiro deles o da existência - consiste em um pressuposto para a análise dos demais (KOMATSU, 1991). Diante disso, sobrevém a compreensão de que "o elemento existência é a base de que dependem os outros elementos" (MELLO, 2012, p. 134; ALVIM, 2017, p. 169). 
Para Cândido Rangel Dinamarco, o ato processual é inexistente "quando the falta algum dos requisitos mínimos caracterizadores do tipo que ele aparenta reproduzir". E, especificamente quanto a esses requisitos mínimos, o autor destaca que eles consistem, cumulativamente, em: (i) forma estabelecida em lei; (ii) agente apto à prática do ato; (iii) declaração de vontade do sujeito; e (iv) objeto que seja admitido em direito (DINAMARCO, 2005, p. 586-587). As consequências da inexistência de um ato processual são a sua incapacidade para a produção de efeitos; a sua insuscetibilidade de ser acobertado pela coisa julgada material (DINAMARCO, 2005, p. 589); e a impossibilidade de convalidação (CABRAL, 2010).

Com a constatação de existência do ato processual, sucede-se a sua travessia para o plano da validade. Nessa dimensão, será verificado se o ato processual existente é perfeito ou imperfeito (MELLO, 2014) e se está de "acordo com as regras jurídicas" previstas para a sua prática (KOMATSU, 1991, p. 34). Conforme observa Teresa Arruda Alvim, o exame da validade do ato processual visa a "evitar que o ato inválido produza efeitos programados ou para fazer cessar os efeitos que eventualmente já estejam sendo produzidos" (ALVIM, 2017, p. 111). E, para tanto, caso as normas que definem os requisitos para o ato processual sejam desobedecidas, a consequência jurídica será a rejeição do ato (MELLO, 2014).

Assim, se o ato imperfeito for declarado nulo, a tendência é que ele se torne ineficaz, deixando de produzir efeitos no mundo jurídico. No entanto, tendo-se em vista que há atos válidos que são ineficazes, pode-se dizer que nem sempre a ineficácia é decorrente da invalidade (ALVIM, 2017). Nesse sentido, conforme bem observado por Roque Komatsu, "o plano da eficácia, como o da validade, pressupõe a passagem do fato jurídico pelo plano da existência, não, todavia, inevitavelmente, pelo plano da validade" (KOMATSU, 1991, p. 35).

Aplicando-se o plano da eficácia especificamente em relação à sentença, Cândido Rangel Dinamarco aponta que esse ato processual pode produzir três tipos de efeitos: os principais, os secundários e os processuais. Os efeitos principais são aqueles desejados pelas partes e explícitos na sentença; os secundários não são expressamente declarados na sentença e também não são necessariamente desejados pelas partes e pelo magistrado, mas derivam da lei; e os processuais consistem em "terminar o ofício do juiz de primeiro grau jurisdicional" e em "pôr termo à primeira fase do processo, a cognitiva" (DINAMARCO, 2009, 311-314).

Assim, uma vez analisados os três planos do mundo jurídico, faz-se necessário examinar os defeitos dos atos processuais sob o prisma dos princípios que entremeiam o instituto. A importância desse estudo justifica-se, sobretudo, em razão de eles orientarem o sistema de nulidades no âmbito do Processo Civil. 


\subsection{PRINCÍPIOS GERAIS PERTINENTES AO ESTUDO DOS DEFEITOS DOS ATOS PROCESSUAIS}

O exame dos princípios referentes ao estudo dos defeitos dos atos processuais revela-se indispensável, visto que eles são utilizados "para verificar a aptidão dos atos processuais para produzir efeitos e se os mesmos atingiram seus fins". Além disso, a compreensão dos princípios auxilia no entendimento dos conceitos abertos, presentes na legislação relativa aos defeitos dos atos processuais (CABRAL, 2010, p. 43).

Demonstrada a pertinência da análise dos princípios para o fim de nortear o estudo da presente disciplina, possibilita-se o ingresso no exame dos princípios que recebem destaque na disciplina: do prejuízo, do interesse, da causalidade e da instrumentalidade das formas (CABRAL, 2016).

O princípio do prejuízo é amplamente conhecido pelo brocardo oriundo do direito francês "pas de nullité sans grief". Ao demonstrar a magnitude desse princípio, José Maria Tesheiner refere que "só é nulo o ato sancionado, expressamente, pelo juiz, com a invalidade, e isso só ocorre quando há prejuízo" (TESHEINER, 2000, p. 121). Essa regra está prevista, fundamentalmente, no artigo 282, parágrafo $1^{\circ}$ e no artigo 283, parágrafo único, ambos do Código de Processo Civil de 2015 (BRASIL, 2015).

O segundo princípio - do interesse - consiste na ideia de que as nulidades não são passíveis de serem suscitadas por quem lhes deu causa (BEDAQUE, 2011). Isso significa que elas podem ser alegadas apenas por quem for inocente (CABRAL, 2010), ou seja, pela parte interessada (THEODORO JÚNIOR, 2011). Diz-se que o objetivo desse princípio é privilegiar a ética e a boa-fé processual (DINAMARCO, 2005), vedando-se ao litigante tirar proveito da sua própria torpeza (ALVIM, 2017). O fundamento legal dessa regra está no artigo 276 do Código de Processo Civil de 2015 (BRASIL, 2015). Essa diretriz somente é aplicável em relação às nulidades relativas e não às absolutas (CINTRA; GRINOVER; DINAMARCO, 2015).

O princípio da instrumentalidade das formas, por sua vez, é considerado pelos estudiosos como a regra mais importante no âmbito do sistema de nulidades (THEODORO JÚNIOR, 2011). Sua base legal encontra-se nos artigos 188 e 277, ambos do Código de Processo Civil de 2015 (BRASIL, 2015). De acordo com essa regra, não será decretada a nulidade do ato processual, ainda que ele tenha algum vício formal, se a sua finalidade for atingida e não causar prejuízo às partes. Essa regra perpassa pela compreensão de que a forma é apenas um meio que possibilita o alcance do fim (GRECO, 2015).

Outro princípio relevante ao presente estudo é o da causalidade. Ele decorre da noção de que o procedimento ${ }^{1}$ é um conjunto de atos processuais (NEVES, 2015) e, em vista disso, eles não podem ser analisados de forma isolada, mas devem sê-lo a partir do seu encadeamento lógico e cronológico (CABRAL,

\footnotetext{
${ }^{1}$ A respeito da conceituação e da distinção entre processo e procedimento, reporta-se à Subseção 1.1 do presente artigo.
} 
2010). Segundo essa diretriz, considerando que os atos processuais são interligados uns aos outros, caso um deles venha a ser anulado, isso afetará todos os atos subsequentes que dele dependam (CINTRA; GRINOVER; DINAMARCO, 2015). Essa regra está prevista no artigo 281 do Código de Processo Civil de 2015 e também irradia seus reflexos na primeira parte do artigo 282 do mesmo diploma legal (BRASIL, 2015).

\section{LITISCONSÓRCIO}

Na segunda parte do artigo serão expostos os aspectos fundamentais do litisconsórcio. À vista disso, será segmentado de modo a viabilizar o estudo das premissas conceituais e dos fundamentos do instituto; o exame dos seus critérios de classificação e de admissibilidade; bem como a reflexão acerca da sua origem e da sua evolução no Brasil.

\subsection{CONSIDERAÇÕES INTRODUTÓRIAS: PREMISSAS CONCEITUAIS E FUNDAMENTOS DO INSTITUTO}

O processo civil moderno, conforme ensinamento de Cândido Rangel Dinamarco, "é essencialmente um processo de partes e sem elas não se concebe como possa o processo formar-se, desenvolver-se, caminhar e chegar aos objetivos jurisdicionais" (DINAMARCO, 2009, p. 21). Nessa perspectiva, pode-se perceber que, consoante bem acentuado por Jonathan lovane de Lemos, as partes possuem especial relevância e a sua participação no âmbito do processo consiste em um requisito de legitimação da atividade jurisdicional (LEMOS, 2013).

No entanto, não há um consenso sobre o conceito de parte, sendo célebre a dissidência doutrinária existente entre Giuseppe Chiovenda e Enrico Tullio Liebman (SICA, 2011). Diante da divergência apresentada entre esses dois autores e a fim de promover uma melhor elucidação acerca do conceito de parte, Cândido Rangel Dinamarco adverte que, para que se tenha uma noção de "parte do processo", é necessário terse em consideração o "direito-garantia" (BOTELHO, 2010, p. 97) constitucional do contraditório. A partir dessa noção, o autor define que o "conceito puro de parte" envolve o "sujeito interessado sobre cuja esfera jurídica incide o provimento jurisdicional" (DINAMARCO, 2009, p. 22-23 e 26; CÂMARA, 2012, p. 149-150).

A despeito das divergências apresentadas relativamente ao conceito de parte, há consenso no sentido de que a definição de terceiro "decorre de uma exclusão lógica do conceito de parte" (EID, 2016, p. 30). Entretanto, muito embora o terceiro interessado passe a integrar a relação processual, isso não implica, automaticamente, na assunção da condição de parte (MARINONI; ARENHART, 2011, p. 159-163). 
O esquema mínimo do processo é formado pela sua configuração tríplice, composta pela presença do autor, do juiz e do réu. Contudo, essa formação - comumente abordada pelas figuras geométricas do triângulo e do ângulo - ${ }^{2}$ trata-se apenas do modo mais simples de analisar a conformação subjetiva do processo. Em razão disso, Luiz Guilherme Marinoni e Sérgio Cruz Arenhart destacam que o importante é "tomar esse arcabouço básico em sua forma simplesmente estrutural, pensando os três sujeitos não como indivíduos, mas como polos na relação processual" (MARINONI; ARENHART, 2011, p. 159).

Com isso, permite-se entender que, por vezes, poderá ocorrer a alteração do esquema mínimo da configuração subjetiva processual. Isso porque, em razão da complexidade das relações, pode ser imposta ou possibilitada a participação de mais indivíduos no polo ativo, no polo passivo, ou em ambos os polos. Esse fenômeno é denominado de pluralidade de partes e, logicamente, aplica-se em relação aos sujeitos considerados "partes do processo" (MILMAN, 2007, p. 45-46).

A pluralidade de partes litigantes - também intitulada de "sujeitos plúrimos de um processo só" (DINAMARCO, 2009, p. 33) - subdivide-se fundamentalmente em duas categorias: a intervenção de terceiros e o litisconsórcio (BEDAQUE, 2016). Diante disso, sem se olvidar da ligação existente entre os dois institutos que, ao fim e ao cabo, vinculam-se em razão de pertencerem ao gênero pluralidade de partes, é possivel conceituá-los, percebendo-se a distinção entre eles (DINAMARCO, 2009).

Assim, pode-se definir a intervenção de terceiros como "o ingresso de um terceiro em processo pendente" (LIEBMAN, 2005, p. 149). Por outro lado, o litisconsórcio, por sua vez, consiste na presença de mais de um sujeito em um dos polos do processo - ativo ou passivo - ou em ambos, figurando como autores ou alvos da pretensão deduzida em juízo (BUENO, 2013).

A partir disso, verifica-se que a vinculação entre esses dois institutos deriva da compreensão de que a consequência acarretada pela intervenção de um terceiro no processo pendente é que ele figurará "como parte, ao lado do autor ou do réu, ou auxiliará uma das partes, ou, ainda, assumirá uma posição própria". Dessarte, quando o terceiro interveniente ocupar a posição de autor ou de réu, em conjunto com outro indivíduo, será ocasionada a situação de litisconsórcio (GRECO, 2015, p. 473).

\footnotetext{
${ }^{2}$ Ao analisar a organização e a estruturação do processo civil sob o enfoque do Estado Democrático de Direito, Jonathan lovane de Lemos observa que a alusão à configuração triangular da relação processual é obsoleta (LEMOS, 2013, p. 133-134). Em sentido contrário, Fabio Milman adere à configuração triangular da relação jurídica (MILMAN, 2007, p. 45).
} 
As principais razões de existir do litisconsórcio consistem na economia processual e na harmonia entre os julgados, de forma a evitar a ocorrência de decisões conflitantes. Esses dois vetores, segundo Elie Pierre Eid, "servem de justificativa para compreender as razões pelas quais se admite reunião de demandas ou de pessoas em um mesmo processo" (EID, 2016, p. 56). Com vista a esses fundamentos, Heitor Vitor Mendonça Sica indica que são gerados, ao Estado, "ganhos em termos de economia e de estabilidade", oportunizando a solução, de forma otimizada, das demandas judiciais (SICA, 2011, p. 13-70).

Estabelecidas essas noções basilares em torno do litisconsórcio, passar-se-á a analisar as particularidades do instituto, de forma a melhor entendê-lo. Dessarte, a seguir será realizado o estudo minucioso das diversas classificações frequentemente utilizadas no âmbito doutrinário, bem como dos critérios de admissibilidade, exemplificando-os com o escopo de consolidar a sua compreensão.

\subsection{CRITÉRIOS DE CLASSIFICAÇÃO E DE ADMISSIBILIDADE}

Para melhor compreender o litisconsórcio, a doutrina brasileira costuma classificá-lo utilizando-se de quatro critérios (DINAMARCO, 2009, p. 69-70): (i) posição ocupada pelos litisconsortes no processo; (ii) momento de formação; (iii) obrigatoriedade ou não de formação; e (iv) tratamento dado pela sentença no plano do direito material. Assim, tendo-se em consideração essa sistematização dos diversos critérios de classificação do instituto, viabiliza-se a sua apreciação da forma a seguir exposta (MILMAN, 2007, p. 49-51).

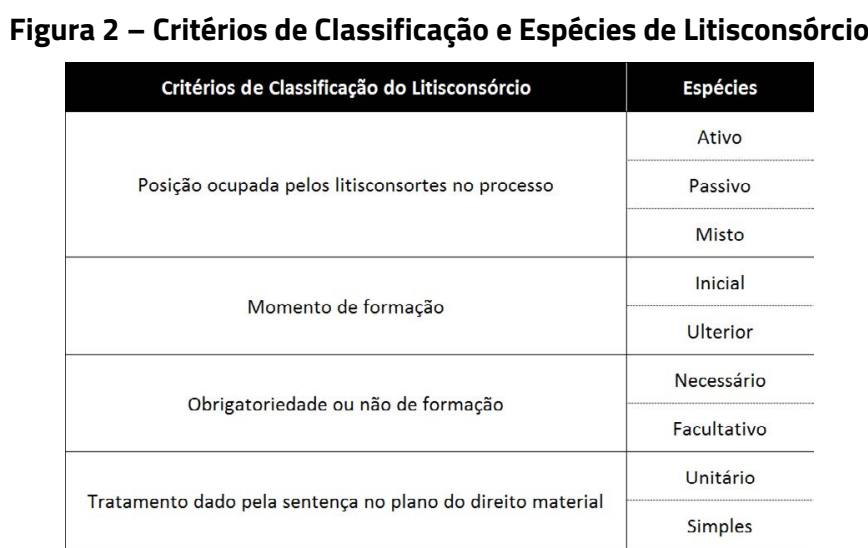

Fonte: Compilação dos autores a partir de Fabio Milman. 
Com relação ao primeiro critério de classificação - posição ocupada pelos litisconsortes no processo - diz-se que o litisconsórcio poderá ser ativo, passivo ou misto, a depender do polo no qual estiver instalado (GRECO, 2015).

No quedizrespeito ao momento de formação do litisconsórcio, permite-sea sua classificação em inicial ou ulterior. Denomina-se de litisconsórcio inicial ou originário aquele que se forma contemporaneamente à propositura da ação. Do contrário, quando a sua formação ocorre em algum momento diferente desse, ocasiona-se o litisconsórcio ulterior ou superveniente (CÂMARA, 2012).

O terceiro critério de classificação refere-se à necessariedade e à facultatividade do litisconsórcio. Segundo Fabio Milman, esse parâmetro "respeita, de um lado, a uma imposição, ou legal, ou advinda do plano do próprio direito material, e, de outro, a conveniência dos sujeitos" quanto à formação do litisconsórcio (MILMAN, 2007, p. 49). Assim, tem-se que, enquanto o primeiro forma-se independentemente da vontade das partes, o segundo decorre da sua iniciativa (MARINONI; ARENHART, 2011).

Conforme se depreende do artigo 114 do Código de Processo Civil de 2015, "o litisconsórcio será necessário por disposição de lei ou quando, pela natureza da relação jurídica controvertida, a eficácia da sentença depender da citação de todos que devam ser litisconsortes" (BRASIL, 2015). Já o litisconsórcio facultativo ocorre quando "as partes podem pretender litigar em conjunto ou podem pretender litigar em face de mais de um réu ao mesmo tempo" (BUENO, 2013, p. 66). Nesse caso, as hipóteses em que a lei autoriza esse litígio conjunto estão previstas no artigo 113 do Código de Processo Civil de 2015 (BRASIL, 2015).

Por fim, o quarto critério de classificação do litisconsórcio diz respeito ao tratamento dado pela sentença no plano do direito material, fracionando-se em unitário ou simples. Esse parâmetro diz respeito à "forma pela qual a sentença resolverá o mérito da demanda, tratando como única persona a todos litisconsortes ou, modo outro, a cada litisconsorte como titular de destino exclusivo"(MILMAN, 2007, p. 51).

Segundo Athos Gusmão Carneiro, o litisconsórcio assumirá contornos unitários quando o destino de todos os litisconsortes for o mesmo (CARNEIRO, 2010, p. 09). Por outro lado, quando o litisconsórcio for simples ou comum, o destino de cada litisconsorte independerá do destino dos demais, incumbindo ao magistrado - que terá "liberdade para julgar de modos diferentes as pretensões ou situações dos diversos litisconsortes" (DINAMARCO, 2009, p. 144) - analisar individualmente a situação de cada um (CÂMARA, 2012).

Uma vez superada essa etapa de conceituação e diferenciação das diversas espécies de classificação do instituto, faz-se importante destacar que elas podem ser cumuladas de forma a gerar diferentes combinações (BUENO, 2013), pois o seu exame é realizado sob ângulos distintos. Isso quer dizer que há a possibilidade de existirem casos concretos com "hipóteses de litisconsórcio necessário unitário, 
de litisconsórcio necessário simples, de litisconsórcio facultativo unitário, de litisconsórcio facultativo simples" (CARNEIRO, 2010, p. 08).

Uma vez compreendidos os diversos critérios classificatórios que orientam o estudo do instituto no direito processual civil brasileiro, afigura-se imprescindivel o exame histórico-evolutivo tanto da legislação quanto da doutrina pátria - que possibilitou e influenciou o aperfeiçoamento da técnica legislativa ao longo dos anos. Para tanto, serão analisadas as principais legislações que deram origem ao estudo da matéria e que foram as bases para o início da sua abordagem no Brasil. Em seguida, aprofundar-se-á o conhecimento no que concerne aos códigos processuais civis brasileiros mais recentes - de 1939, de 1973 e de 2015.

\subsection{ORIGEM E EVOLUÇÃO DO LITISCONSÓRCIO NO BRASIL}

A matéria atinente ao litisconsórcio foi regulada sistematicamente, pela primeira vez, no Código de Processo Civil alemão de 1877. No Brasil, a primeira previsão legislativa que admitiu o instituto foi a Lei $n^{\circ} 221$, datada de 20 de novembro de 1894. De acordo com Guilherme Estellita, essa legislação "francamente permitiu o litisconsórcio, sem que os autores ou réus estivessem presos a uma única relação jurídica", tendo recebido forte influência do direito português (ESTELLITA, 1955, p. 27) e, também, do alemão (BARBOSA MOREIRA, 1989).

Posteriormente, houve o advento da Constituição Republicana de 1891, estabelecendo-se, no país, a dualidade de competência, ou seja, a competência da União Federal e dos Estados-membros para legislarem sobre Direito Processual (BARBOSA MOREIRA, 1989). Com isso, sobreveio o período dos códigos estaduais (EID, 2016) e o Estado do Rio Grande do Sul, no ano de 1906, foi o precursor no trato da matéria, muito embora não o tenha feito de forma acurada (ESTELLITA, 1955).

Após, sucederam-se outros textos legais que previram o litisconsórcio. E, no ano de 1934, foi promulgada a Constituição da República dos Estados Unidos do Brasil (BRASIL, 1934), que instituiu a unificação do direito processual e determinou a elaboração dos novos códigos de processo (ESTELLITA, 1955). Dessa forma, sobreveio o Código de Processo Civil de 1939, contendo previsões a respeito do litisconsórcio em seu Capítulo II do Título VIII do Livro I (BRASIL, 1939).

Ainda na vigência do Código de Processo Civil de 1939, concebeu-se o termo "litisconsórcio unitário" e foram tecidas críticas aos artigos 88, 89 e 90 da legislação com o escopo de, sobretudo, demonstrar 
como se conciliariam as "formas de litisconsórcio com os regimes litisconsorciais". Todas essas observações e análises em torno da legislação foram essenciais para a evolução do tema no código de processo civil subsequente (EID, 2016, p. 79-80).

Dessa forma, atento às críticas engendradas em torno da legislação processual civil de 1939, o legislador do Código de Processo Civil de 1973 tomou cautela para não "associar a necessariedade do litisconsórcio a qualquer das hipóteses de sua genérica admissibilidade", afastando-se da premissa de que a comunhão tornaria o litisconsórcio indispensável (DINAMARCO, 2009, p. 110). Nessa época, também adveio o entendimento doutrinário a respeito da autonomia entre o litisconsórcio unitário e o necessário. No entanto, ainda que tenha havido evolução legislativa no tocante a alguns pontos, o Código Buzaid "não foi capaz de expressar com precisão os ensinamentos vindos da doutrina construída até então", repetindo problemas relacionados à "confusão entre litisconsórcio necessário e unitário" (EID, 2016, p. 81).

Em recente estudo, Heitor Vitor Mendonça Sica observou que o artigo 47 do Código de Processo Civil de 1973 (BRASIL, 1973), "em realidade descreveu o fenômeno do litisconsórcio unitário que, para a maioria da doutrina nacional", não se confunde com o litisconsórcio necessário. Diante de tal quadro, adotou-se a interpretação de acordo com a doutrina majoritária - liderada pelos ensinamentos de José Carlos Barbosa Moreira - no sentido de que as duas classificações não se misturam (SICA, 2016, p. 65-86).

Dessa forma, com o advento do Código de Processo Civil de 2015, buscou-se suprir as deficiências existentes na legislação anterior e houve, ao menos, a tentativa do Código de Processo Civil de 2015 em solver o problema atinente a "como se desenha a validade e eficácia da sentença proferida em processo desprovido da integração de litisconsorte necessário" (SICA, 2016, p. 65-86).

Outros grandes avanços do atual Código de Processo Civil foram a conceituação de litisconsórcio necessário e o reconhecimento do litisconsórcio unitário como uma categoria autônoma (EID, 2016, p. 84). Nessa linha, percebe-se que o texto legal segmentou as duas figuras nos artigos 114 e 116 do Código de Processo Civil de 2015 (BRASIL, 2015), respectivamente, suprindo algumas falhas apresentadas na legislação precedente (EID, 2016, p. 84-85).

Diante disso, pode-se verificar que, conquanto a legislação tenha demonstrado expressiva evolução no trato da matéria, ainda restam grandes discussões acerca de determinados pontos - sobretudo em torno das disposições do artigo 115 do Código de Processo Civil. Dessa forma, afigura-se necessário o aprofundamento do estudo no tocante a esse dispositivo legal e às diversas correntes doutrinárias que o circundam. 


\section{A SENTENÇA DE MÉRITO PROLATADA COM A PRETERIÇÃO DO(S) LITISCONSORTE(S) NECESSÁRIO(S) UNITÁRIO(S): UMA ANÁLISE SOB A ÓTICA DOS PLANOS DOS ATOS PROCESSUAIS}

Com o suporte conquistado na leitura das Seções precedentes, adentrar-se-á na problemática principal do artigo: em qual dos planos dos atos processuais - existência, validade ou eficácia - está situado o defeito que acomete a sentença de mérito prolatada sem a presença do(s) litisconsorte(s) necessário(s) unitário(s). Com vistas a esse objetivo, esta seção será organizada a fim de proporcionar, inicialmente, o conhecimento dos posicionamentos doutrinários a respeito da temática; após, será realizada a análise crítica da opção legislativa adotada pelo Código de Processo Civil de 2015; e, por último, identificar-se-ão as vias processuais admissíveis para combater essa sentença.

\subsection{EXISTÊNCIA, VALIDADE E EFICÁCIA: POSICIONAMENTOS DOUTRINÁRIOS DIVERGENTES E CONVERGENTES}

De acordo com a doutrina recente, o tópico objeto do presente estudo ainda causa "sensivel divergência de opiniões", reunindo estudiosos que se coadunam com a concepção de que, nesses casos, o vício encontra-se nos planos da existência ou da validade, até chegar aos que adotam a tese da ineficácia (EID, 2016, p. 152-153).

O primeiro posicionamento - de que o defeito está situado no plano da existência - é defendido por processualistas como Teresa Arruda Alvim (ALVIM, 2017), Willis Santiago Guerra Filho (GUERRA FILHO, 2006) e André de Luizi Correia (CORREIA, 2001). O principal fundamento dessa tese é o de que, estando ausente algum litisconsorte necessário unitário, não terá sido perfectibilizada a citação de todos aqueles que deveriam ter integrado a relação jurídica processual. Desse modo, uma vez que eles consideram a citação válida como um pressuposto de existência do processo, a sentença será juridicamente inexistente (NEVES, 2015).

Ocorre que, consoante bem observado por Cassio Scarpinella Bueno, a opinião desses autores não é acompanhada por significativa parcela da doutrina (BUENO, 2013). Exemplo disso são os processualistas José Carlos Barbosa Moreira, Fredie Didier Júnior, Luiz Guilherme Marinoni e Daniel Mitidiero que, sob outra perspectiva, assentem com a tese de que o vício dessa sentença opera-se no plano da validade. Ao explicar o seu entendimento, esses autores esclarecem que, no caso em apreço, justamente porque a sentença de mérito deve obrigatoriamente ser uniforme em relação aos litisconsortes é que toda ela 
estará irremediavelmente maculada, merecendo uma consequência jurídica rigorosa, qual seja, a nulidade (BARBOSA MOREIRA, 1972; DIDIER JÚNIOR, 2012).

Sob outro viés, há estudiosos - como Guilherme Estellita (ESTELLITA, 1955), Giuseppe Chiovenda (CHIOVENDA, 1993), José Maria Rosa Tesheiner (TESHEINER, 2000), Enrico Tullio Liebman (LIEBMAN, 2005), Fabio Milman (MILMAN, 2007), Cândido Rangel Dinamarco (DINAMARCO, 2009) e Elie Pierre Eid (EID, 2016), entre outros (LAMBAUER, 1982; CAMARGO SOBRINHO, 2002; BARBI, 2008; CARNEIRO, 2010; CÂMARA, 2012; BUENO, 2013; WAMBIER; TALAMINI, 2015) - que analisam o problema e o explicam sustentando a noção de ineficácia dessa sentença de mérito (CORREIA, 2001).

Os adeptos desse entendimento destacam que, conquanto a ineficácia dessa sentença seja absoluta, ela não será integral. Isso quer dizer que ao menos os efeitos processuais ${ }^{3}$ dessa decisão serão produzidos. Contudo, analisando-se a situação sob o prisma subjetivo, essa mesma decisão é considerada absolutamente ineficaz, pois estará dotada de inaptidão para irradiar os seus efeitos tanto com relação aos sujeitos que participaram do processo quanto aos que foram omitidos (CHIOVENDA, 1993); ela será ineficaz para todos (LIEBMAN, 2005).

Cândido Rangel Dinamarco salienta que o escopo de classificar essa sentença como ineficaz é o respeito ao devido processo legal que possui a sua estrutura delineada de modo a assegurar e a permitir que todos esses colegitimados participem do contraditório instituído perante o juízo. Por essa razão, aqueles que foram privados desse direito precisam ter a sua esfera jurídica preservada e não podem ficar sujeitos aos efeitos da decisão dada sem a sua presença (DINAMARCO, 2009).

Diante de todo o acima exposto, verifica-se que há divergências entre os estudiosos no que concerne ao plano no qual está situado o defeito da sentença de mérito após o seu trânsito em julgado. Todavia, há de se realçar a existência de um ponto com relação ao qual confluem os processualistas anteriormente mencionados: ${ }^{4}$ antes de transitada em julgado a sentença de mérito prolatada sem a presença de algum litisconsorte necessário unitário, o defeito estará situado no plano da validade (MILMAN, 2007; EID, 2016; ALVIM, 2017), dando ensejo à nulidade da decisão (CAMARGO SOBRINHO, 2002).

Essa nulidade, antes do trânsito em julgado, é classificada pelos autores como "absoluta embora não cominada em lei", uma vez que diz respeito a uma matéria de ordem pública, podendo a decisão ser anulada pelos tribunais, ainda que de ofício. No entanto, em respeito aos princípios das nulidades processuais, não

\footnotetext{
${ }^{3}$ Quanto aos efeitos da sentença - principais, secundários e processuais - consultar a segunda subseção da seção I do presente artigo.

${ }^{4}$ Com exceção de Enrico Tullio Liebman que não se posiciona quanto ao ponto (LIEBMAN, 2005, p. 142-146).
} 
deve ocorrer a anulação do processo em sua totalidade, mas somente dos atos dependentes da citação e ulteriores a ela (DINAMARCO, 2009, p. 296-298 e 301-306).

\subsection{ANÁLISE CRÍTICA DA OPÇÃO LEGISLATIVA ADOTADA PELO CÓDIGO DE PROCESSO CIVIL DE 2015}

Como visto na Subseção precedente, a preocupação em solucionar esse debate é antiga e dá azo a muitos debates (EID, 2016). Tanto assim o é que, recentemente, ao tecer comentários acerca do Código de Processo Civil de 2015, Luiz Dellore anteviu acertadamente que o assunto continuaria sendo "objeto de rica polêmica", mesmo com o advento da nova legislação processual que, com o objetivo de pacificar o tema, passou a prevê-lo em seu artigo 115 (DELLORE, 2015, p. 781).

Da leitura desse dispositivo legal associada ao conhecimento granjeado na Seção anterior, nota-se que o legislador buscou afirmar que a sentença de mérito prolatada sem a presença de algum litisconsorte necessário unitário será absolutamente nula, tendo o seu defeito situado no plano da validade. E, nas demais situações, estatuiu-se que o vício dessa decisão está assentado no plano da eficácia, uma vez que a decisão terá os seus efeitos limitados às partes do processo (DELLORE, 2015).

Apesar da ausência de referência do mencionado dispositivo legal ao plano da existência, cumpre verificar o motivo pelo qual se descarta, desde logo, a possibilidade de que o vício dessa sentença se encontre nesse plano (EID, 2016). Nessa linha, segundo Cândido Rangel Dinamarco, a conclusão de que o defeito se encontra no plano da existência não é a mais acertada, pois:

A sentença existe quando presentes os elementos essenciais que a configuram como tal: que contenha um dispositivo, que seja proferida por pessoa investida de jurisdição, que esteja incluída em um processo etc [...].

Só quanto a uma sentença que exista, obviamente, pode-se cogitar da produção de efeitos: a que não existe não produz nem os processuais nem os substanciais, primários ou secundários. Por isso, descarta-se desde logo que seja inexistente a sentença dada sem a presença de todos os colegitimados indispensáveis. Ela produz ao menos os efeitos processuais de uma sentença [...] (DINAMARCO, 2009, p. 315-316). 
Além disso, rechaça-se a tese de invalidade dessa sentença, visto que o sistema de nulidades dos atos processuais comporta análise exclusivamente no campo endoprocessual. E, considerando que "as nulidades são vicissitudes da vida do processo", elas "perdem todo o significado quando ele se extingue, tornando-se irrecorrivel a sentença dada". Com isso, percebe-se que a essência da questão está no plano da eficácia e para a sua verificação é necessário identificar os efeitos principais da decisão. Nessa linha, Elie Pierre Eid explica que essa decisão será existente, mas "haverá óbice na completa materialização de todos os efeitos que a sentença poderia produzir", (EID, 2016, p. 159).

Outro ponto importante que se pode destacar no dispositivo legal em estudo é que, do seu exame minucioso, torna-se possível identificar a ausência de determinação específica a respeito do momento ao qual ele se refere - se anterior ou posterior ao trânsito em julgado da sentença de mérito (BRASIL, 2015). Com isso, ao invés de atenuar as divergências a respeito da omissão litisconsorcial, o legislador acabou por potencializá-las (GRECO, 2015, p. 470). Isso porque, como visto, essa definição detém superlativa importância (BARBI, 2008, p. 210).

Portanto, conclui-se que "o sistema de nulidades processuais não explica suficientemente o fenômeno das sentenças de mérito proferidas sem a presença de todos os co-legitimados indispensáveis" (CAMARGO SOBRINHO, 2002, p. 122). Assim, verifica-se que a legislação é carente de precisão a respeito dessa temática (EID, 2016).

A relevância desse estudo ultrapassa questões meramente terminológicas, repercutindo consequências, sobretudo, na esfera recursal, uma vez que os regimes atinentes a cada um dos planos dos atos processuais são diferentes (BUENO, 2013). Dessa forma, mostra-se fundamental o estudo das formas de combater a sentença de mérito prolatada com o alijamento de algum litisconsorte necessário unitário.

\subsection{VIAS PROCESSUAIS ADMISSIVVEIS PARA COMBATER A SENTENÇA INUTILITER DATUR}

É comum, no âmbito doutrinário, denominar a sentença em estudo como inutiliter datur. Essa expressão latina, segundo Elie Pierre Eid, é um ensinamento de Giuseppe Chiovenda utilizado para o fim de expressar a ineficácia das sentenças de mérito prolatadas quando há a omissão de algum litisconsorte necessário unitário (EID, 2016; CARNEIRO, 2010). 
Uma vez assentado que, antes do trânsito em julgado, ${ }^{5}$ essa sentença é dotada de nulidade (MILMAN, 2007) e que, após o trânsito em julgado, ela é ineficaz, constata-se que há dois momentos distintos para analisar as formas de combater essa decisão (EID, 2016). Assim, doravante identificar-se-ão quais são as vias processuais admissíveis para combatê-la.

Até a prolatação da sentença, pode ocorrer o suprimento da omissão do(s) litisconsorte(s) necessário(s) unitário(s), consistindo em um vício sanável (CAMARGO SOBRINHO, 2002). Isso significa que o magistrado tem o dever de, ao identificar o vício, ordenar que sejam tomadas as providências previstas no parágrafo único do artigo 115 do Código de Processo Civil (BRASIL, 2015). Na eventualidade de não ser detectado esse defeito e a sentença ser prolatada, sobrevirá o chamado error in procedendo (NERY JÚNIOR, 2014), decorrente da omissão de um ato imprescindivel ao procedimento (DINAMARCO, 2009).

Em razão disso, "flagrado o vício em sede de apelação, deve a sentença ser tida como nula e os autos remetidos ao primeiro grau para que, depois de citado(s) o(s) litisconsorte(s) faltante(s), seja outra sentença proferida" (ALVIM, 2017, p. 402). Logicamente, a anulação provinda dos tribunais respeitará os princípios atinentes à matéria - tais como o princípio do prejuízo, do interesse, da causalidade e da instrumentalidade das formas. ${ }^{6}$ E, "após feita a citação do litisconsorte antes faltante", ser-lhe-á oportunizada a defesa, honrando-se os direitos-garantias constitucionais - em especial o contraditório (DINAMARCO, 2009, p. 301-302), fazendo-se valer o caráter dialético do processo, conferindo igualdade de oportunidades a todas as partes (BOTELHO, 2010).

Portanto, até a prolatação da sentença, tem-se que o defeito é sanável a qualquer tempo, comportando suprimento. De outra banda, após o pronunciamento judicial e antes do seu trânsito em julgado, o vício da preterição litisconsorcial consiste em uma nulidade absoluta que "comporta consideração exclusivamente endoprocessual para que, pendente ainda o processo, o ato imperfeito, ou contaminado por defeito anterior" seja declarado nulo. Essa endoprocessualidade decorre da ideia de que "visando assegurar o resultado prático e concreto do processo", ocorrerá o trânsito em julgado que tornará a sentença irrecorrivel, impedindo a modificação da decisão (CAMARGO SOBRINHO, 2002, p. 121-122).

No entanto, analisando-se a sentença inutiliter datur após o seu trânsito em julgado, tem-se que, embora ela exista e seja válida, ela é aparentemente eficaz. Isso quer dizer que, conquanto essa decisão

\footnotetext{
${ }^{5}$ Para maiores esclarecimentos acerca da importância do trânsito em julgado como marco divisor para determinar a nulidade ou a ineficácia da sentença de mérito prolatada com a omissão do(s) litisconsorte(s) necessário(s) unitário(s), faz-se referência à linha de raciocínio desenvolvida nas Subseções 3.1 e 3.2 do presente artigo.

${ }^{6}$ A temática atinente aos princípios pertinentes ao estudo dos defeitos dos atos processuais foi exposta na Subseção 1.3 da presente pesquisa, ao qual se reporta.
} 
esteja eivada de vício, admite-se que ela produziu os seus efeitos processuais e, além disso, que caso ela tenha natureza preponderantemente condenatória, valerá como título executivo hábil a deflagrar a execução forçada (DINAMARCO, 2009).

Em contrapartida, é consabido que essa decisão está procedimentalmente maculada, deixando de produzir os seus efeitos perante os indivíduos que integraram o contraditório e preteridos. Diante disso, considerando que a sentença inutiliter datur sequer teve o intuito de destinar-se ao litisconsorte omitido, bem como que ela é existente e válida, não se pode simplesmente desconsiderar esse ato estatal, tornando-se imperiosa a utilização das vias processuais admissíveis para combatê-la, a fim de declará-la inoperante (DINAMARCO, 2009).

A linha doutrinária é no sentido de que essa ineficácia "pode ser reconhecida por qualquer meio processual idôneo" (CÂMARA, 2012, p. 161). Com isso, a parte tem a faculdade de suscitar a ineficácia tanto por ação rescisória quanto por querela nullitatis insanabilis ou por impugnação ao cumprimento da sentença ou, ainda, por qualquer outra via processual que seja "compativel com a situação concreta", inexistindo ordem de preferência (MARINONI; MITIDIERO, 2017, p. 40) e incidindo o princípio da fungibilidade recursal (NERY JÚNIOR, 2014). Por fim, observa-se que, dada a incindibilidade da relação jurídica, todos os litisconsortes - os omitidos e os não omitidos - possuirão interesse de agir e legitimidade para a alegação (ALVIM, 2017).

\section{CONSIDERAÇÕES FINAIS}

Ao longo dos tópicos abordados no presente artigo foi possível perceber, inicialmente, a importância dos atos processuais para a compreensão e o desenvolvimento da entidade complexa denominada processo, bem como que os defeitos dos atos processuais podem ser analisados sob a ótica dos planos da existência, da validade e da eficácia, sendo que cada um deles possui características próprias e, por isso, ressoam consequências jurídicas distintas.

Na sequência, observou-se que os princípios atinentes ao estudo dos defeitos dos atos processuais - em especial o do prejuízo, do interesse, da causalidade e da instrumentalidade das formas - revelam-se de extrema importância para orientar o juiz quanto à decretação da nulidade ou da anulabilidade do ato processual, constituindo verdadeiras diretrizes para a aferição da ocorrência, ou não, das nulidades, bem como da sua extensão na esfera processual.

A partir da segunda Seção, procedeu-se ao estudo do litisconsórcio, espécie do gênero pluralidade de partes. Nesse ponto, percebeu-se a distinção entre os conceitos de parte do processo, de parte da 
demanda e de terceiro. Com isso, constatou-se que o litisconsórcio ocorre quando há a presença de mais de um sujeito em um dos polos do processo, ou em ambos, figurando como autores ou como alvos da pretensão deduzida em juízo. Ademais, identificou-se que a economia processual e a harmonia entre os julgados são os vetores que governam o instituto, servindo como fundamento para a admissibilidade da reunião dos colegitimados no processo.

Subsequentemente, classificou-se o litisconsórcio e observou-se que, apesar da expressiva evolução da legislação no trato da matéria, ainda persistem pontos que provocam avivadas discussões no âmbito doutrinário, a exemplo da problemática principal do presente artigo.

Compreendidas essas noções basilares, adentrou-se na análise dos posicionamentos divergentes e convergentes sobre a temática em estudo. Para tanto, foram abordadas as teses de inexistência, de invalidade e de ineficácia da sentença de mérito prolatada sem a presença do(s) litisconsorte(s) necessário(s) unitário(s). E, por todo o estudo desenvolvido, assentou-se que, na eventualidade de a alegação ocorrer anteriormente ao trânsito em julgado, o defeito estará situado no plano da validade, tratando-se de uma nulidade absoluta. Por outro lado, após o trânsito em julgado, o que remanesce é o vício no plano da eficácia. Com isso, denotou-se que a legislação processual civil brasileira atual não é incorreta, mas incompleta e carente de precisão, pois é omissa com relação à indicação do momento processual a que se refere, potencializando as dúvidas a respeito da temática.

Ao final, verificou-se que, devido à gravidade desse defeito, tanto o litisconsorte preterido quanto o que integrou a relação jurídica processual detêm legitimidade para arguir a ineficácia da sentença inutiliter datur, por meio do manejo da ação rescisória, da impugnação ao cumprimento de sentença, da querela nullitatis insanabilis ou, ainda, de qualquer outro meio idôneo e compativel com a situação concreta.

\section{REFERÊNCIAS}

ALVIM, Teresa Arruda. Nulidades do Processo e da Sentença. 8. ed. rev. atual. e ampl. São Paulo: Revista dos Tribunais, 2017.

BARBI, Celso Agrícola. Comentários ao Código de Processo Civil. Rio de Janeiro: Forense, 2008.

BARBOSA MOREIRA, José Carlos. A Influência do Direito Processual Civil Alemão em Portugal e no Brasil. Revista de Processo. v. 56, p. 100-109, out./dez. 1989. Disponivel em: <http://www.revistadostribunais. com.br/maf/app/resultList/document? \&src=rl\&srguid=iOad82d9a0000015f2027d839f813c4d0\&docg uid=Icb42e790008711e1968d00008558bdfc\&hitguid=Icb42e 790008711e1968d00008558bdfc\&spo$\mathrm{s}=3 \&$ epos=3\&td=5\&context=8\&crumb-action=append\&crumb-label=Documento\&isDocFG=false\&is FromMulti Summ=\&startChunk=1\&endChunk=1 >. Acesso em: 29 nov. 2017. 
BARBOSA MOREIRA, José Carlos. Litisconsórcio Unitário. Rio de Janeiro: Forense, 1972.

BEDAQUE, José Roberto dos Santos. Breves notas sobre o litisconsórcio no Novo Código de Processo Civil. Revista Brasileira da Advocacia. v. 3, p. 189-206, out./dez. 2016. Disponivel em: <http://www. revistadostribunais.com.br/maf/app/resultList/document?\&src=rl\&srguid=iOad82d9a0000015f2027d839f813c4d0\&docguid=Icb42e790008711e1968d00008558bdfc\&hitguid=Icb42e790008711e1968d00008558bdfc\&spos=3\&epos=3\&td=5\&context=8\&crumb-action=append\&crumb-label=Documento\&isDocFG=false\&isFromMulti Summ=\&startChunk=1\&endChunk=1>. Acesso em: 27 mar. 2017.

BEDAQUE, José Roberto dos Santos. Nulidade processual e instrumentalidade do processo. Revista de Processo. v. 60, p. 31-43, out./dez. 1990. Doutrinas Essenciais de Processo Civil. v. 3, p. 985-1003, out. 2011. Disponivel em: <http://www.revistadostribunais.com.br/maf/app/resultList/document?\&src=rI\&srguid=iOad6adc60000015d0605f80e7cf95b51\&docguid=1350e13e02d5511e0baf30000855dd350\&hitguid=1350e13e02d5511e0baf30000855dd350\&spos=1\&epos=1\&td=3\&context=8\&crumb-action=append\&crumb-label=Documento\&isDocFG=false\&isFromMulti Summ=\&startChunk=1\&endChunk=1>. Acesso em: 09 nov. 2017.

BOTELHO, Guilherme. Direito ao processo qualificado: o processo civil na perspectiva do estado constitucional. Porto Alegre: Livraria do Advogado, 2010.

BRASIL. Presidência da República. Constituição da República dos Estados Unidos do Brasil, de 16 de Julho de 1934. Disponível em: <http://www.planalto.gov.br/ccivil_03/constituicao/constituicao34.htm>. Acesso em: 24 out. 2017.

Presidência da República. Decreto-Lei n 1.608, de 18 de setembro de 1939. Código de Processo Civil. Disponivel em: <http://www.planalto.gov.br/ccivil_03/decreto-lei/1937-1946/Del1608. htm>. Acesso em: 26 out. 2017.

Presidência da República. Lei n 13.105, de 16 de março de 2015. Institui o Código de Processo Civil. Disponível em: <http://www.planalto.gov.br/ccivil_03/_ato2015-2018/2015/lei//13105.htm>. Acesso em: 08 mar. 2017.

Presidência da República. Lei n 5.869, de 11 de janeiro de 1973. Institui o Código de Processo Civil. Disponível em: <http://www.planalto.gov.br/ccivil_03/leis/L5869impressao.htm>. Acesso em: 07 nov. 2017.

BUENO, Cassio Scarpinella. Partes e Terceiros no Processo Civil Brasileiro. São Paulo: Saraiva, 2013.

CABRAL, Antonio do Passo. Nulidades no Processo Moderno: Contraditório, Proteção da Confiança e Validade Prima Facie dos Atos Processuais. 2. ed. Rio de Janeiro: Forense, 2010. 
CABRAL, Antonio do Passo. Teoria das nulidades processuais no direito contemporâneo. Revista de Processo. v. 255, p. 117-140, mai 2016. Disponivel em: <http://www.revistadostribunais.com.br/maf/app/ resultList/document?\&src=rl\&srguid=i0ad82d9a0000015d0501b2b6ab5ebc57\&docguid=lefa6894007 a211e08920010000000000\& hitguid=lefa6894007a211e08920010000000000\&spos=1\&epos=1\&$\mathrm{td}=56 \&$ context=17\&crumb-action=append\&crumb-label=Documento\&isDocFG=false\&isFrom MultiSumm=\&startChunk=1\&endChunk=1>. Acesso em: 18 mai. 2017.

CÂMARA, Alexandre Freitas. Lições de Direito Processual Civil. 22. ed. Rio de Janeiro: Lumen Juris, 2012, v. 1.

CAMARGO SOBRINHO, Mário de. Do litisconsórcio e seus efeitos: Um estudo sobre os aspectos fundamentais da pluralidade de partes à luz do CPC. São Paulo: Interlex, 2002.

CARNEIRO, Athos Gusmão. Intervenção de terceiros. 19. ed. São Paulo: Saraiva, 2010.

CASTRO, Honildo Amaral de Mello. Nulidades. Princípios Constitucionais e Processuais. Revista dos Tribunais. v. 761, p. 45-63, mar. 1999. Disponível em: <http://www.revistadostribunais. com.br/maf/app/resultList/document?\&src=rl\&srguid=iOad6adc60000015d060c464dbdf4c86b\&docguid=lae79af40f25011dfab6f010000000000\&hitguid=lae79af40f25011dfab6f010000000000\&spos=1\&epos=1\&td=4\&context=24\&crumb-action=append\&crumb-label=Documento\&isDocFG=false\&isFromMulti Summ=\&startChunk=1\&endChunk=1>. Acesso em: 25 out. 2017.

CHIOVENDA, Giuseppe. Sul litisconsorzio necessario. In: Saggi di Diritto Processuale Civile. Milano: Giuffrè, 1993, v. 2.

CINTRA, Antonio Carlos de Araújo; GRINOVER, Ada Pellegrini; DINAMARCO, Cândido Rangel. Teoria Geral do Processo. 31. ed. rev. e ampl. São Paulo: Malheiros, 2015.

CORREIA, André de Luizi. A citação no direito processual civil brasileiro. São Paulo: Revista dos Tribunais, 2001, v. 46. (Coleção Estudos de Direito de Processo - Enrico Tullio Liebman).

CUNHA, Leonardo Carneiro da. Dos atos processuais. In: CABRAL, Antonio do Passo; CRAMER, Ronald (Coord.). Comentários ao Novo Código de Processo Civil. Rio de Janeiro: Forense, 2015.

DALL'AGNOL JÚNIOR, Antonio Janyr. Invalidades Processuais. Porto Alegre: Letras Jurídicas, 1989.

DELLORE, Luiz. Do Litisconsórcio. In: GAJARDONI, Fernando da Fonseca et al. Teoria Geral do Processo Comentários ao CPC de 2015: Parte Geral. São Paulo: Forense, 2015.

DIDIER JÚNIOR, Fredie. Curso de Direito Processual Civil. 17. ed. rev. ampl. e atual. Salvador: JusPodivm, 2015, v. 1: Introdução ao direito processual civil, parte geral e processo de conhecimento. 
DIDIER JÚNIOR, Fredie. Litisconsórcio Unitário e Litisconsórcio Necessário. Revista de Processo. v. 208, p. 407-422, jun. 2012. Disponivel em: <http://www.revistadostribunais.com.br/maf/app/resultList/document?\&src=rl\&srguid=i0ad82d9a0000016149e419eeaf06f142\&docguid=la81c7a60b83d11e1ac3f000085592b66\&hitguid=la81c7a60b83d11e1ac3f000085592b66\&spos=1\&epos=1\&td=488\&context=11\&crumb-action=append\&crumb-label=Documento\&isDocFG=true\&isFrom MultiSumm=true\&startChunk=1\&endChunk=1>. Acesso em: 22 nov. 2017.

DINAMARCO, Cândido Rangel. Instituições de Direito Processual Civil. 5. ed. rev. e atual. São Paulo: MaIheiros, 2005, v. 2: 0 método de exercício da jurisdição: processo.

DINAMARCO, Cândido Rangel. Litisconsórcio. 8. ed. rev. atual. São Paulo: Malheiros, 2009.

EID, Elie Pierre. Litisconsórcio Unitário: Fundamentos, estrutura e regime. São Paulo: Revista dos Tribunais, 2016. (Coleção Liebman).

ESTELLITA, Guilherme. Do Litisconsórcio no Direito Brasileiro. Rio de Janeiro: [s.n.], 1955.

FAZZALARI, Elio. Instituições de Direito Processual. Tradução de Elaine Nassif. 1. ed. Campinas: Bookseller, 2006.

GAIO JÚNIOR, Antônio Pereira; GOMES, Júlio César dos Santos; FAIRBANKS, Alexandre de Serpa Pinto. Negócios jurídicos processuais e as bases para a sua consolidação no CPC/2015.

Revista de Processo. v. 267, p. 43-73, mai. 2017. Disponivel em: <http://www.revistadostribunais.com.br/maf/app/resultList/document?\&src=rl\&srguid=iOad82d9a0000015ede941b6959674a12\&docguid=Icda5be4020cf11e7b2cc010000000000\&hitguid=Icda5be4020cf11e7b2cc010000000000\&spos=2\&epos=2\&td=4000\&context=6\&crumb-action=append\&crumb-label=Documento\&isDocFG=false\&isFrom MultiSumm=\&startChunk=1\&endChunk=1 >. Acesso em: 18 set. 2017.

GONÇALVES, Aroldo Plínio. Nulidades no Processo. Rio de Janeiro: Aide, 1993.

GRECO, Leonardo. Instituições de Processo Civil. Rio de Janeiro: Forense, 2015, v. 1: Introdução ao Direito Processual Civil.

GUERRA FILHO, Willis Santiago. Nota sobre a necessariedade do litisconsórcio e a garantia do direito fundamental ao contraditório. In: FUX, Luiz; NERY JÚNIOR, Nelson; WAMBIER, Teresa Arruda Alvim. Processo e Constituição. São Paulo: Revista dos Tribunais, 2006.

KOMATSU, Roque. Da invalidade no processo civil. São Paulo: Revista dos Tribunais, 1991.

LAMBAUER, Mathias. Do litisconsórcio necessário. São Paulo: Saraiva, 1982. 
LEMOS, Jonathan lovane de. A organização do processo civil: uma análise cultural da estruturação do processo. Rio de Janeiro: Lumen Juris, 2013.

LIEBMAN, Enrico Tullio. Manual de Direito Processual Civil. Tradução de Cândido Rangel Dinamarco. 3. ed. São Paulo: Malheiros, 2005, v.1.

MARINONI, Luiz Guilherme; ARENHART, Sérgio Cruz. Curso de Processo Civil. 10. ed. rev. e atual. São Paulo: Revista dos Tribunais, 2011, v. 2: Processo de Conhecimento.

MARINONI, Luiz Guilherme; MITIDIERO, Daniel. Ação Rescisória: Do Juízo Rescindente ao Juízo Rescisório. São Paulo: Revista dos Tribunais, 2017.

MELLO, Marcos Bernardes de. Teoria do fato jurídico: plano da existência. 18. ed. São Paulo: Saraiva, 2012.

MELLO, Marcos Bernardes de. Teoria do fato jurídico: plano da validade. 13. ed. São Paulo: Saraiva, 2014.

MILMAN, Fabio. Partes, procuradores, litisconsórcio e intervenção de terceiros. Porto Alegre: Verbo Jurídico, 2007.

MITIDIERO, Daniel Francisco. O problema da invalidade dos atos processuais no direito processual civil brasileiro contemporâneo. Revista de Direito Processual Civil. Curitiba: Gênesis, v. 35, 2005. Disponível em: <http://www.abdpc.org.br/abdpc/artigos/Daniel\%20Francisco\%20Mitidiero\%20-\%20formatado.pdf>. Acesso em: 22 fev. 2017.

NERY JÚNIOR, Nelson. Teoria Geral dos Recursos. 7. ed. rev. e atual. São Paulo: Revista dos Tribunais, 2014.

NEVES, Daniel Amorim Assumpção. Manual de Direito Processual Civil. 7. ed. São Paulo: Método, 2015.

PASSOS, José Joaquim Calmon de. Esboço de uma teoria das nulidades aplicada às nulidades processuais. 1. ed. Rio de Janeiro: Forense, 2002.

PONTES DE MIRANDA, Francisco Cavalcanti. Tratado das Ações. 1. ed. Campinas: Bookseller, 1999, t. 1: Ações, Classificação e Eficácia.

SICA, Heitor Vitor Mendonça. Notas críticas ao sistema de pluralidade de partes no processo civil brasileiro. Revista de Processo. v. 200, p. 13-70, out. 2011. Disponivel em: <http://www.revistadostribunais. com.br/maf/app/resultList/document?\&src=rl\&srguid=iOad82d9a0000015f2027d839f813c4d0\&docg uid=Icb42e790008711e1968d00008558bdfc\&hitguid=Icb42e790008711e1968d00008558bdfc\&spo- 


\section{Gestãoe \\ Desenvolvimento}

e-ISSN: 2446-6875

p-ISSN: 1807-5436

$\mathrm{s}=3 \&$ epos=3\&td=5\&context=8\&crumb-action=append\&crumb-label=Documento\&isDocFG=false\&is FromMulti Summ=\&startChunk=1\&endChunk=1>. Acesso em: 15 out. 2017.

SICA, Heitor Vitor Mendonça. Três velhos problemas do processo litisconsorcial à luz do CPC/2015. Revista de Processo. v. 256, p. 65-86, jun. 2016. Disponível em: <http://www.revistadostribunais.com.

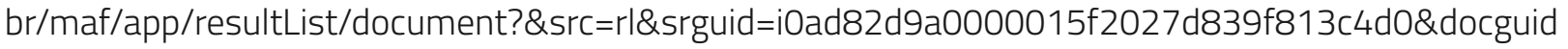
$=$ Icb42e790008711e1968d00008558bdfc\&hitguid=Icb42e 790008711e1968d00008558bdfc \&spo$\mathrm{s}=3 \&$ epos=3\&td=5\&context=8\&crumb-action=append\&crumb-label=Documento\&isDocFG=false\&is FromMulti Summ=\&startChunk=1\&endChunk=1 >. Acesso em: 30 out. 2017.

TESHEINER, José Maria Rosa. Pressupostos processuais e nulidades no processo civil. São Paulo: Saraiva, 2000.

THEODORO JÚNIOR, Humberto. As nulidades no Código de Processo Civil. Revista de Processo. v. 30, p. 38-60, abr./jun. 1983. Doutrinas Essenciais de Processo Civil. v. 3, p. 911-942, out. 2011. Disponivel em: <http://www.revistadostribunais.com.br/maf/app/resultList/document?\&src=rl\&srguid=i0ad82d9a0000015d0501b2b6ab5ebc57\&docguid=lefa6894007a211e08920010000000000 \&hitguid=lefa6894007a211e08920010000000000\&spos=1\&epos=1\&td=56\&context=17\&crumb-action=append\&crumb-label=Documento\&isDocFG=false\&isFrom MultiSumm=\&startChunk=1\&endChunk=1 >. Acesso em: 12 jul. 2017.

WAMBIER, Luiz Rodrigues; TALAMINI, Eduardo. Curso Avançado de Processo Civil. 15. ed. rev. e atual. São Paulo: Revista dos Tribunais, 2015, v. 1: Teoria geral do processo e processo de conhecimento. 